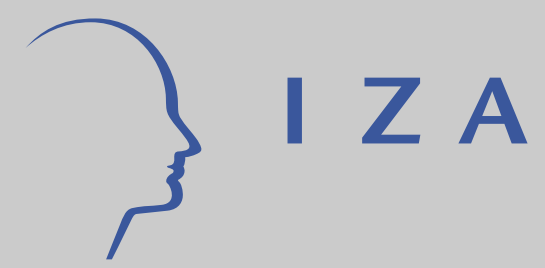

IZA DP No. 5330

Universities as Stakeholders in their Students' Careers:

On the Benefits of Graduate Taxes to Finance Higher

Education

Tom McKenzie

Dirk Sliwka

November 2010

Forschungsinstitut zur Zukunft der Arbeit Institute for the Study of Labor 


\title{
Universities as Stakeholders in their Students' Careers: On the Benefits of Graduate Taxes to Finance Higher Education
}

\author{
Tom McKenzie \\ Dirk Sliwka \\ University of Cologne \\ and IZA
}

Cass Business School, City University London

Discussion Paper No. 5330

November 2010

\author{
IZA \\ P.O. Box 7240 \\ 53072 Bonn \\ Germany \\ Phone: +49-228-3894-0 \\ Fax: +49-228-3894-180 \\ E-mail: iza@iza.org
}

\begin{abstract}
Any opinions expressed here are those of the author(s) and not those of IZA. Research published in this series may include views on policy, but the institute itself takes no institutional policy positions.

The Institute for the Study of Labor (IZA) in Bonn is a local and virtual international research center and a place of communication between science, politics and business. IZA is an independent nonprofit organization supported by Deutsche Post Foundation. The center is associated with the University of Bonn and offers a stimulating research environment through its international network, workshops and conferences, data service, project support, research visits and doctoral program. IZA engages in (i) original and internationally competitive research in all fields of labor economics, (ii) development of policy concepts, and (iii) dissemination of research results and concepts to the interested public.
\end{abstract}

IZA Discussion Papers often represent preliminary work and are circulated to encourage discussion. Citation of such a paper should account for its provisional character. A revised version may be available directly from the author. 
IZA Discussion Paper No. 5330

November 2010

\section{ABSTRACT \\ Universities as Stakeholders in their Students' Careers: On the Benefits of Graduate Taxes to Finance Higher Education}

We examine ways of funding higher education, comparing upfront tuition fees with graduate taxes. The tax dominates, as volatility in future income is transferred from risk-averse students to the risk-neutral state. However, a double moral hazard problem arises when students' efforts to raise lifetime income and universities' activities to improve teaching quality are endogenized. We show that graduate taxes reduce work incentives but provide incentives to improve teaching quality. Yet if tax revenues are distributed evenly among universities there is free riding. To solve this problem each university should be allocated the revenue generated by its own alumni. In addition, we demonstrate how a budget-balancing graduate tax would encourage more people to attend university than would the equivalent upfront tuition fee.

JEL Classification: H42, H52, I22, M52

Keywords: $\quad$ higher education, graduate tax, tuition fees, risk aversion, incentives

Corresponding author:

Dirk Sliwka

University of Cologne

Patrizia Tower

Venloer Straße 151-153

50672 Köln

Germany

E-mail: dirk.sliwka@uni-koeln.de 


\section{Introduction}

The funding of public university education is the subject of current debate across Europe. ${ }^{1}$ In several countries including Germany, university courses have traditionally been funded entirely by the state and discussion has focused on the introduction of tuition fees. In the United Kingdom, universities have been charging students tuition fees for the past decade but they are not sufficient to cover the costs of education and there is much resistance to increasing them beyond present levels. We acknowledge the pressing need to have students participate in the financing of their studies. However, there is significant risk involved in successfully completing a university course and securing future employment. We therefore question whether upfront tuition fees represent an efficient funding model. The government in the United Kingdom recently proposed a tax following graduation from university as an alternative to tuition fees and the idea has since been embraced by the leader of the opposition (Financial Times, 2010). In this article we consider these two different means of financing higher education from both the students' and the universities' perspectives.

There is some previous literature on the issue of graduate taxes. Eaton and Rosen (1980) demonstrate in their analysis that a linear income tax can increase incentives for risk-averse individuals to invest in human capital. When the returns to such investments are uncertain, the state effectively takes on a part of the risk via the tax. García-Peñalosa and Wälde (2000) build on this result, relating it to the funding of higher education. They compare a graduate tax to loan schemes. The graduate tax is preferred to student loans due to such insurance effects. It is also superior to general taxation when equity in the economy as a whole is considered. Gary-Bobo and Trannoy (2005) assume that wages are a function of learnable skill and innate ability. The authors focus on tuition fees and analyze the decision to study and student selection on the part of universities under this regime.

In our model, we compare a system of tuition fees with a proportional graduate tax on future income. The state continues to fund the universities up to a certain point. Beyond this point, the students are responsible for financing their education. When there is no moral hazard problem, we too

\footnotetext{
${ }^{1}$ For a survey of developments in higher education and an international overview of funding models see The Economist (2005). For an introduction to the various forms of university funding, see Barr (1993).
} 
obtain the general result that risk-averse students prefer the graduate tax, as future income is volatile, and the risk-neutral state assumes part of this risk via the tax. However, since students differ in their abilities, highly able students are likelier to prefer an upfront fee as they expect to pay more tax than their less able counterparts later on.

We then introduce two levels of moral hazard into the model. First, we allow future income to depend on costly, unobservable effort on the part of graduates. Subsequently, we incorporate moral hazard with regard to teaching quality provided by universities. We hence end up with a double moral hazard problem, as has been analyzed in various contexts, for instance by Cooper and Ross (1985), Demski and Sappington (1991), Romano (1994) and Bhattacharyya and Lafontaine (1995). We find that while a graduate tax reduces the incentives for graduates to work hard, it also leads to higher teaching quality as long as the revenues are shared among the universities. The reason is that universities stand to profit from the higher future income of their former students (which they can affect by raising teaching quality). However, if revenues from the tax are distributed evenly among universities a free-rider problem exists. This problem can be solved if each university is allowed to receive the revenues raised from the tax paid by its own former students. In such a system, universities become stakeholders in their students' future careers. Each university has high incentives to improve teaching quality as this increases its students' human capital, in turn leading to higher future wages and thus higher tax revenue, which benefits the university directly.

The paper is structured as follows. In the next section, we introduce the basic model. In section three, we consider a reference case where teaching quality is an exogenous variable. In section four we endogenize both graduate effort at the workplace and the quality of teaching at university. In section five, we determine whether a graduate tax or tuition fees would lead to a higher number of school-leavers applying for a university degree course. Section six concludes. 


\section{Basic model}

We consider a country in which there are $n$ equally sized publicly owned universities. Let there be a continuum of students $I=[0,1]{ }^{2}$ Each student $i \in I$ has constant absolute risk aversion $r>0$ and utility function $u(w)=-e^{-r w}$ where $w$ is the individual's lifetime income. Students vary in their ability, captured by the variable $a_{i}$; abilities are normally distributed across the population of students $a_{i} \sim N\left(m_{a}, \sigma_{a}^{2}\right)$. There are two periods in the model. In the first period, the students attend university. In the second period, each student (now a graduate) earns income which depends on his human capital and some random component. The human capital of a graduate is a function of his ability and the quality of the university education $q$ which we first treat as exogenously given. We assume that abler students benefit more from a higher quality of education. ${ }^{3}$ Hence, the second-period wage of individual $i$ is

$$
W_{i}=q a_{i}+\varepsilon_{i}
$$

where $\varepsilon_{i} \sim N\left(0, \sigma_{\varepsilon}^{2}\right)$. We assume that $\varepsilon_{i}$ and $a_{i}$ are uncorrelated. The total cost of education is $K$. Our risk-neutral state provides $B<K$ from an education budget to cover part of this cost. To finance the rest, the state now faces a choice between an upfront tuition fee per student $\alpha$ and a proportional graduate tax on future income $\beta$. We make the reasonable assumption that the future income of university graduates is sufficient to cover the cost of their education

$$
q m_{a}>K-B
$$

\footnotetext{
${ }^{2}$ We first assume that the population of students is of fixed size. In section five we endogenize the decision to study at university and consider which form of funding would lead to more applications.

${ }^{3}$ This is well in line with results from personnel psychology showing that in nearly all jobs people with higher cognitive abilities build up more knowlege and skills than others and do so faster. See for instance the discussion in Schmidt and Hunter (1998).
} 


\section{A reference case}

We first consider the case where teaching quality is an exogenous variable. The state's budget constraint with a fixed fee $\alpha$ is

$$
\int_{0}^{1} \alpha d i=K-B
$$

Hence, the budget-balancing fixed fee is given by $\alpha=K-B$. When a graduate tax is imposed, the budget constraint is

$$
\beta \int_{0}^{1} q a_{i} d i=K-B
$$

The graduate tax rate covering the budget deficit is hence

$$
\beta=\frac{K-B}{q m_{a}} .
$$

We now compare the utility of an individual student $i$ with ability $a_{i}$ under the two systems. Given our assumption that students are risk averse with constant absolute risk aversion the certainty equivalent of student $i$ with a fixed fee is ${ }^{4}$

$$
E\left[q a_{i}+\varepsilon_{i}-\alpha\right]-\frac{1}{2} r \cdot \operatorname{Var}\left[q a_{i}+\varepsilon_{i}-\alpha\right]
$$

and with a graduate tax it is

$$
E\left[(1-\beta)\left(q a_{i}+\varepsilon_{i}\right)\right]-\frac{1}{2} r \cdot \operatorname{Var}\left[(1-\beta)\left(q a_{i}+\varepsilon_{i}\right)\right] .
$$

First, suppose that the state, having a utilitarian welfare function, selects the system that maximizes the expected utility of students, taking into account the distribution of abilities. Note that this corresponds to the choice of an individual student acting under a 'veil of ignorance', i.e. not yet knowing his own individual ability. We obtain the following result:

Proposition 1 If the state maximizes the expected utility of the students it will implement the graduate tax.

\section{Proof:}

\footnotetext{
${ }^{4}$ See for instance Wolfstetter (1999), p. 342.
} 
The graduate tax is preferred if (3) exceeds (2) taking into account that abilities are normally distributed. Let $\sigma_{W}^{2}=\operatorname{Var}\left[q a_{i}+\varepsilon_{i}\right]=q^{2} \sigma_{a}^{2}+\sigma_{\varepsilon}^{2}$. The graduate tax is preferred iff

$$
\begin{gathered}
(1-\beta) q m_{a}-\frac{1}{2} r(1-\beta)^{2} \sigma_{W}^{2} \geq q m_{a}-\alpha-\frac{1}{2} r \sigma_{W}^{2} \\
\Leftrightarrow \frac{1}{2} r \sigma_{W}^{2}\left[1-(1-\beta)^{2}\right] \geq \beta q m_{a}-\alpha .
\end{gathered}
$$

Substituting the (binding) budget constraints for $\alpha$ and $\beta$, we obtain

$$
\begin{gathered}
\frac{1}{2} r \sigma_{W}^{2}\left[1-\left(1-\frac{K-B}{q m_{a}}\right)^{2}\right] \geq \frac{K-B}{q m_{a}} q m_{a}-(K-B) \\
\Leftrightarrow \frac{1}{2} r \sigma_{W}^{2}\left[1-\left(1-\frac{K-B}{q m_{a}}\right)^{2}\right] \geq 0 .
\end{gathered}
$$

From the viability condition (1) we have that $q m_{a}>K-B$. Hence, the inequality always holds.

Note that the state here decides as an individual student would, were he oblivious to his own ability. The reason that the graduate tax is preferred to an upfront tuition fee is that through the tax, the risk-neutral state insures the risk-averse students against uncertainty in their future incomes.

However, individual students typically will have information regarding their abilities and may differ in their preferences about the system. We therefore investigate individual students' preferences for one of the systems when the state is only interested in balancing the budget and find:

Proposition 2 Students up to a threshold ability level $\widehat{a_{i}}$ prefer the graduate tax. Beyond this cut-off value, students of high ability $a_{i}>\widehat{a_{i}}$ prefer the upfront fee. The threshold $\widehat{a_{i}}$ is greater than the median (mean) ability $m_{a}$.

\section{Proof:}

Student $i$ will prefer the graduate tax if and only if $(3) \geq(2)$. This inequality 
is equivalent to

$$
\begin{gathered}
(1-\beta) q a_{i}-\frac{1}{2} r(1-\beta)^{2} \sigma_{\varepsilon}^{2} \geq q a_{i}-\alpha-\frac{1}{2} r \sigma_{\varepsilon}^{2} \\
\Leftrightarrow \frac{1}{2} r \sigma_{\varepsilon}^{2}\left[1-(1-\beta)^{2}\right] \geq \beta q a_{i}-\alpha .
\end{gathered}
$$

Substituting the (binding) budget constraints for $\alpha$ and $\beta$, we obtain

$$
\begin{gathered}
\frac{1}{2} r \sigma_{\varepsilon}^{2} \frac{K-B}{q m_{a}}\left(2-\frac{K-B}{q m_{a}}\right) \geq \frac{K-B}{q m_{a}} q a_{i}-(K-B) \\
\Leftrightarrow \frac{1}{2} r \sigma_{\varepsilon}^{2} \frac{1}{q m_{a}}\left(2-\frac{K-B}{q m_{a}}\right) \geq \frac{a_{i}}{m_{a}}-1 \\
\Leftrightarrow a_{i} \leq m_{a}+\frac{1}{2} r \sigma_{\varepsilon}^{2} \frac{1}{q}\left(2-\frac{K-B}{q m_{a}}\right)=: \widehat{a_{i}} .
\end{gathered}
$$

From the viability condition (1) we have that $q m_{a}>K-B$. It follows that the median student will also prefer the graduate tax $m_{a}<\widehat{a_{i}}$.

The graduate tax still has an insurance effect from the perspective of an individual student. But when abilities are known, this insurance effect only covers the unsystematic fluctuations $\varepsilon_{i}$. In addition, the tax redistributes income from the abler to the less able students. Students of low ability benefit more from the graduate tax. They will earn less in the future and therefore have to pay less. However, very able students anticipate their relatively high expected future incomes and would thus prefer to pay the standard fee today in return for not having to subsidize the education of others through their earnings later. Hence, if $a_{i}$ is large enough, the costs from redistribution outweigh individual risk concerns.

Nevertheless, a student of median ability always prefers the graduate tax. The reason for this is that the median student pays the same under both systems in expected terms but still profits from the insurance effect of the graduate tax. Hence, a median voter model would predict that majority voting between the two systems lead to the choice of a graduate tax. 


\section{Moral hazard}

In this section we compare the incentive effects of the graduate tax and fixed tuition fee on graduate effort at the workplace and on university provision of teaching quality. We start by analyzing the moral hazard problems separately and then consider an integrated model.

\subsection{Graduate moral hazard}

In reality, income not only depends on the quality of a university education. It also depends on a graduate's effort once he or she is in employment. We now modify our wage function to include the effects of graduate effort $e_{i}$, with convex cost of effort $C\left(e_{i}\right)=\frac{c}{2}\left(e_{i}-\bar{e}\right)^{2}$, where $\bar{e}$ is the level of voluntary effort provided by a graduate. We assume that the effects of higher ability and higher effort complement each other:

$$
W_{i}\left(q, e_{i}, a_{i}, \varepsilon_{i}\right)=\left(q+e_{i}\right) a_{i}+\varepsilon_{i} .
$$

We obtain the following result:

Proposition 3 The fixed tuition fee provides higher work incentives for graduates.

\section{Proof:}

The certainty equivalent with the tuition fee (2) now becomes

$$
\left(q+e_{i}\right) a_{i}-\alpha-\frac{c}{2}\left(e_{i}-\bar{e}\right)^{2}-\frac{1}{2} r \sigma_{\varepsilon}^{2}
$$

The student chooses the effort level that maximizes the above expression. The first order condition is

$$
\begin{gathered}
a_{i}-c\left(e_{i}-\bar{e}\right)=0 \\
\Leftrightarrow e_{i}=\bar{e}+\frac{a_{i}}{c} .
\end{gathered}
$$


The certainty equivalent under the graduate tax (3) becomes

$$
(1-\beta)\left(q+e_{i}\right) a_{i}-\frac{c}{2}\left(e_{i}-\bar{e}\right)^{2}-\frac{1}{2} r(1-\beta)^{2} \sigma_{\varepsilon}^{2} .
$$

The student maximizes the above expression with respect to $e_{i}$ for a given $\operatorname{tax} \beta$. The first order condition is

$$
\begin{gathered}
(1-\beta) a_{i}-c\left(e_{i}-\bar{e}\right)=0 \\
\Leftrightarrow e_{i}=\bar{e}+(1-\beta) \frac{a_{i}}{c} .
\end{gathered}
$$

This is $\beta \frac{a_{i}}{c}$ less than the effort exerted under the tuition fee.

Under the tax, graduates effectively only see $(1-\beta)$ of the income they generate. With the fixed fee they remain residual claimants on their income. They thus choose to work less hard compared to the situation with a fixed tuition fee.

\subsection{University moral hazard}

So far we have assumed that teaching quality is exogenous. However, it is quite likely that universities' efforts to improve teaching quality are also affected by the mode of financing higher education. We model this by assuming that revenues from the upfront tuition fee and graduate tax are to be shared equally among the $n$ universities and that each university can affect the teaching quality provided.

Each university $j \in\{1,2, \ldots, n\}$ can expend effort to increase its teaching quality $q_{j}$, investing more in the human capital formation of its students. The (non-monetary) cost of effort of the university staff is $\Gamma\left(q_{j}, s_{j}\right)=$ $\frac{\gamma}{2} s_{j}\left(q_{j}-\bar{q}\right)^{2}$, where $s_{j}$ denotes the mass of students educated by university $j$ and $\bar{q}$ represents the basic teaching quality provided voluntarily by the university, regardless of any external incentives. ${ }^{5}$ We assume that the teaching cost parameter $\gamma$ is greater than the workplace cost parameter $c$ since $\gamma$ is a per-capita measure. ${ }^{6}$ Universities are risk-neutral. Furthermore we assume

\footnotetext{
${ }^{5}$ For simplicity, we have assumed that cost of effort in teaching quality is linear in the number of students. In reality these costs may be concave due to economies of scale. Note that since we have a continuum of students $I=[0,1]$ and $n$ universities with an equal number of students, $s_{j}=\frac{1}{n} \forall j$.

${ }^{6}$ It should not be the case that it cost an individual more to generate a wage increase
} 
for simplicity that the distribution of student abilities is the same at each university and that universities are of equal size. Finally, we assume that each university is interested in maximizing its budget taking into account the effort costs of raising teaching quality.

With a centrally determined upfront fee, the universities have no influence on revenues through teaching quality. As such, each university simply seeks to minimize its cost of effort. It hence chooses $q_{j}=\bar{q}$ and the system provides no additional incentives to raise quality. Under the graduate tax, the universities choose effort so as to maximize their revenue, net of the cost of effort. The total revenue from the graduate tax is

$$
\beta \int_{0}^{1} W_{i} d i=\beta\left[\sum_{l=1}^{n} s_{l} q_{l} m_{a}+\int_{0}^{1}\left[\bar{e}+(1-\beta) \frac{a_{i}}{c}\right] a_{i} d i\right] .
$$

The optimization problem of university $j$ is

$$
\max _{q_{j}} \frac{1}{n} \beta\left[\sum_{l=1}^{n} s_{l} q_{l} m_{a}+\int_{0}^{1}\left[\bar{e}+(1-\beta) \frac{a_{i}}{c}\right] a_{i} d i\right]-\frac{\gamma}{2} s_{j}\left(q_{j}-\bar{q}\right)^{2} .
$$

The first order condition yields

$$
\begin{gathered}
\frac{1}{n} \beta s_{j} m_{a}-\gamma s_{j}\left(q_{j}-\bar{q}\right)=0 \\
\Leftrightarrow q_{j}=\bar{q}+\beta \frac{m_{a}}{n \gamma} .
\end{gathered}
$$

The universities have a stake in providing a better quality of teaching under the graduate tax as they will benefit from the surplus revenues generated through increasing the future wages of their students.

Note the classic free-rider problem among universities. As each university is allocated an equal share of total tax revenue, the marginal revenue from improved teaching quality is lower, the more universities there are (the higher is $n$ ).

Yet there is a straightforward solution to this problem: universities should be allowed to collect tax directly from their own alumni. To analyze this formally, note that in this case the optimization problem of university

through higher direct workplace effort than it costs his university to achieve the same increase indirectly through improved teaching quality. 
$j$ is

$$
\max _{q_{j}} s_{j} \beta q_{j} m_{a}+s_{j} \beta \int_{0}^{1}\left[\bar{e}+(1-\beta) \frac{a_{i}}{c}\right] a_{i} d i-\frac{\gamma}{2} s_{j}\left(q_{j}-\bar{q}\right)^{2}
$$

with first order condition

$$
\begin{aligned}
& s_{j} \beta m_{a}-\gamma s_{j}\left(q_{j}-\bar{q}\right)=0 \\
& \Leftrightarrow q_{j}=q=\bar{q}+\beta \frac{m_{a}}{\gamma} \forall j .
\end{aligned}
$$

Clearly, the quality provided is higher under the direct collection system than when the graduate tax is shared equally among the public universities. Hence, we can conclude:

Proposition 4 When universities set their teaching quality endogenously, graduate taxes provide better incentives for universities to invest in their students' human capital than do fixed tuition fees. These incentives are even stronger when each university receives the tax revenues directly from its own former students.

Thus, such a system would make universities stakeholders in the career success of their students. Universities that find effective new ways to increase their students' human capital are able to share the gains.

\section{Decision to study at university}

In the previous sections students account for the whole population. In this section we relax this assumption, allowing for only a subset of the population to study and focusing on the decision of a school-leaver to apply for a place at university. We again compare the graduate tax with upfront tuition fees and determine which system leads to a higher number of applications.

Let there be a continuum of school-leavers $I=[0,1]$ contemplating whether or not to take a degree course at university. School-leaver $i$ is aware of his or her ability $a_{i}$ and abilities are normally distributed $a_{i} \sim N\left(m_{a}, \sigma_{a}^{2}\right)$. For simplicity, all school-leavers who decide against a university degree will attain a certainty equivalent of $w_{0}$, irrespective of their abilities. But if school-leaver $i$ decides to study, the second-period graduate wage is

$$
W_{i}=q a_{i}+\varepsilon_{i}
$$


where $q$ again stands for the quality of education and $\varepsilon_{i} \sim N\left(0, \sigma_{\varepsilon}^{2}\right)$ represents a random component of future income unbeknown to the school-leaver at the time of applying for a place at university. ${ }^{7}$ We again assume that $\varepsilon_{i}$ and $a_{i}$ are uncorrelated. Suppose now that the per capita costs of education are equal to $\kappa$. Furthermore, we assume that the state can screen the applicants and can set a minimum ability level $a_{\min }$ as a precondition for admission.

With a tuition fee $\alpha$, a school-leaver will apply for university if

$$
\begin{gathered}
E\left[q a_{i}+\varepsilon_{i}-\alpha\right]-\frac{1}{2} r \cdot \operatorname{Var}\left[q a_{i}+\varepsilon_{i}-\alpha\right]>w_{0} \\
\Leftrightarrow q a_{i}-\alpha-\frac{1}{2} r \sigma_{\varepsilon}^{2}>w_{0} \\
\Leftrightarrow a_{i}>\frac{w_{0}+\frac{1}{2} r \sigma_{\varepsilon}^{2}+\alpha}{q} .
\end{gathered}
$$

With a graduate tax $\beta$, a university education is chosen if

$$
\begin{gathered}
E\left[(1-\beta)\left(q a_{i}+\varepsilon_{i}\right)\right]-\frac{1}{2} r \cdot \operatorname{Var}\left[(1-\beta)\left(q a_{i}+\varepsilon_{i}\right)\right]>w_{0} \\
\Leftrightarrow(1-\beta) q a_{i}-\frac{1}{2} r(1-\beta)^{2} \sigma_{\varepsilon}^{2}>w_{0} \\
\Leftrightarrow a_{i}>\frac{w_{0}+\frac{1}{2} r(1-\beta)^{2} \sigma_{\varepsilon}^{2}}{(1-\beta) q} .
\end{gathered}
$$

In the case of a fixed tuition fee, the state can cover its costs by setting $\alpha=\kappa$, regardless of the number of students. With the tax rate, however, voluntary enrolment will not necessarily lead to a balanced budget when the tax rate is small. But the state can always limit enrolment by imposing an appropriate minimum ability requirement.

We now show that more school-leavers will apply for university if the state implements a budget-balancing graduate tax. To see this, we first consider a situation in which the state imposes a fixed fee $\alpha=\kappa$ on all students. In this case, the marginal student, i.e. the one whose ability is just sufficient to warrant a university education rather than employment

\footnotetext{
${ }^{7}$ To reduce the complexity of analysis, we revert to exogenous teaching quality and the basic-model wage that is independent of workplace effort.
} 
directly on finishing school, is characterized by ability

$$
a_{\kappa}=\frac{w_{0}+\frac{1}{2} r \sigma_{\varepsilon}^{2}+\kappa}{q} .
$$

Now suppose instead that the state sets a graduate tax rate $\beta^{\prime}$ leading to exactly the same expected payment by the marginal student as this fee, i.e.

$$
\beta^{\prime} q a_{\kappa}=\kappa \Leftrightarrow \beta^{\prime}=\frac{\kappa}{q a_{\kappa}}=\frac{\kappa}{w_{0}+\frac{1}{2} r \sigma_{\varepsilon}^{2}+\kappa} .
$$

By substituting this tax level into (6) we see that a school-leaver will choose to enrol if

$$
a_{i}>\frac{w_{0}+\frac{1}{2} r\left(1-\frac{\kappa}{w_{0}+\frac{1}{2} r \sigma_{\varepsilon}^{2}+\kappa}\right)^{2} \sigma_{\varepsilon}^{2}}{\left(1-\frac{\kappa}{w_{0}+\frac{1}{2} r \sigma_{\varepsilon}^{2}+\kappa}\right) q}=: a_{\beta} .
$$

Note that $a_{\beta}$ is always smaller than $a_{\kappa}$ as

$$
\begin{gathered}
\frac{w_{0}+\frac{1}{2} r\left(1-\frac{\kappa}{w_{0}+\frac{1}{2} r \sigma_{\varepsilon}^{2}+\kappa}\right)^{2} \sigma_{\varepsilon}^{2}}{\left(1-\frac{\kappa}{w_{0}+\frac{1}{2} r \sigma_{\varepsilon}^{2}+\kappa}\right) q}<\frac{w_{0}+\frac{1}{2} r \sigma_{\varepsilon}^{2}+\kappa}{q} \\
\Leftrightarrow\left(1-\frac{\kappa}{w_{0}+\frac{1}{2} r \sigma_{\varepsilon}^{2}+\kappa}\right)^{2}<1
\end{gathered}
$$

which is always true. Hence, the number of applicants will increase when moving to a graduate tax and imposing this tax rate.

Now we consider the effect of the tax on the state's finances. Recall that by definition, the state always breaks even with the budget-balancing fixed fee. With the tax, the state earns less when students of lower ability choose to enrol. However, costs can be controlled by limiting enrolment and choosing a threshold ability for admission $a_{\min } \in\left[a_{\beta}, a_{\kappa}\right]$. The expected surplus from the tax is then

$$
\begin{gathered}
\int_{a_{\min }}^{\infty}\left(\beta^{\prime} q a_{i}-\kappa\right) f\left(a_{i}\right) d a_{i} \\
=\int_{a_{\min }}^{\infty} \kappa\left(\frac{a_{i}}{a_{\kappa}}-1\right) f\left(a_{i}\right) d a_{i} \\
=\int_{a_{\kappa}}^{\infty} \kappa\left(\frac{a_{i}}{a_{\kappa}}-1\right) f\left(a_{i}\right) d a_{i}+\int_{a_{\min }}^{a_{\kappa}} \kappa\left(\frac{a_{i}}{a_{\kappa}}-1\right) f\left(a_{i}\right) d a_{i} .
\end{gathered}
$$


Note that the first term of this expression (7) is strictly positive. This is due to the fact that with the tax the state collects more money than it spends from all the students who would rather enrol with the fee; although these students would prefer the fee, they continue to enrol with the tax. On the other hand, at the tax rate $\beta^{\prime}$, the state subsidizes those students with ability levels below $a_{\kappa}$. Still, it is always possible to finance such a subsidy out of the additional revenues collected from the more able students. The state simply sets a minimum ability requirement $a_{\min }$ which guarantees that it does not lose money from implementing the graduate tax. The budgetbalancing threshold $\underline{a}_{\min }$ is strictly smaller than $a_{\kappa}$. To see this, note that the budget surplus (7) is strictly positive at $a_{\min }=a_{\kappa}$ and decreases as the admission threshold $a_{\min }$ is lowered.

Hence, we conclude:

Proposition 5 By replacing a budget-balancing tuition fee with a graduate tax, enrolment can be increased without violating the budget constraint.

There are two reasons for this property of the graduate tax. The first is risk aversion; the tax reduces the risk of uncertain returns from studying and in turn increases the school-leaver's willingness to study. This can be seen by comparing the certainty equivalent of the marginal student paying the tax with the alternative certainty equivalent when paying the fee; the former is always higher than the latter:

$$
\begin{gathered}
E\left[(1-\beta)\left(q a_{\kappa}+\varepsilon_{\kappa}\right)\right]-\frac{1}{2} r \cdot \operatorname{Var}\left[(1-\beta)\left(q a_{\kappa}+\varepsilon_{\kappa}\right)\right]> \\
E\left[q a_{\kappa}+\varepsilon_{\kappa}-\alpha\right]-\frac{1}{2} r \cdot \operatorname{Var}\left[q a_{\kappa}+\varepsilon_{\kappa}-\alpha\right] \\
\Leftrightarrow\left(1-\frac{\kappa}{q a_{\kappa}}\right) q a_{\kappa}-\frac{1}{2} r\left(1-\frac{\kappa}{q a_{\kappa}}\right)^{2} \sigma_{\varepsilon}^{2}>q a_{\kappa}-\kappa-\frac{1}{2} r \sigma_{\varepsilon}^{2} \\
\Leftrightarrow\left(1-\frac{\kappa}{w_{0}+\frac{1}{2} r \sigma_{\varepsilon}^{2}+\kappa}\right)^{2}<1 .
\end{gathered}
$$

The second reason for more school-leavers applying with the graduate tax than the fixed tuition fee is price discrimination. The tax results in higher prices for those students with a higher willingness to pay due to their higher abilities, and lower prices for others who are less able with a lower willingness to pay. 


\section{Conclusion and outlook}

We have compared fixed tuition fees to a graduate tax as a means to fund higher education from the perspective of students of differing ability. Applying a utility function with constant absolute risk aversion we were able to show that for risk-averse students, a graduate tax is generally preferable as it insures against fluctuations in future income. We then allowed for universities to invest in teaching quality and for income to depend not only on this quality but also on graduate effort at the workplace. We showed that while the tax is a disincentive for workers to generate income themselves, it acts as an incentive for the universities to improve the quality of education. A key finding is that the tax is most effective when paid directly by graduates to their former universities. In this way, it is possible to overcome the free-rider problem which exists when the state shares tax revenue equally among universities.

One may ask what the effect would be of having tuition fees collected directly by universities. In our model, there are only two periods and the fee is paid only once, thus there would be no direct incentive for universities to increase teaching quality. Were the model extended to more periods or an overlapping-generations setup, long-term reputation considerations would become relevant and implicit incentives would be created. However, reputation would always be built on past teaching quality; the incentives would not be as immediate as those created by the graduate tax scheme.

Barr (2004) advocates a system of loans with income-contingent repayments, which has similar properties to the graduate tax in our analysis. We consider just two systems. Although our students differ in their innate abilities, we do not differentiate between rich and poor students and do not look into grants and loans. Hence, the issue of equity based on initial endowments of wealth does not arise in the model. This might be incorporated via an interest rate that varies between students with respect to their ability to borrow money to pay the upfront fee. Nevertheless, when we endogenize the decision by school-leavers whether or not to apply for university, our analysis demonstrates that a graduate tax would allow a larger proportion of the population to study than the equivalent upfront tuition fee. This is due to the tax exacting price discrimination on the market for higher education in addition to its insurance properties. 
Finally, alumni donations seem to play an increasingly significant role in financing higher education. ${ }^{8}$ Such voluntary contributions presumably arise through graduate preferences for fairness and reciprocity. An interesting extension to the model may thus be to consider the effect of universities anticipating such preferences on their incentives to improve teaching quality.

\section{References}

Barr, Nicholas (1993): Alternative Funding Resources for Higher Education. The Economic Journal, 103, pp. 718-728.

Barr, Nicholas (2004): Higher Education Funding. Oxford Review of Economic Policy, 20(2), pp. 264-283.

Bhattacharyya, S. and Lafontaine, F. (1995): Double-sided moral hazard and the nature of share contracts. Rand Journal of Economics, 26, pp. $761-781$.

Cooper, R. and Ross, T.W. (1985): Product Warranties and Double Moral Hazard. Rand Journal of Economics, 16, pp. 103-113.

Cunningham, Brendan M. and Cochi-Ficano, Carlena K. (2002): Revenue Flows from Alumni of Higher Education - An Empirical Enquiry. The Journal of Human Resources, 37(3), pp. 541-569.

Demski, J.S. and Sappington, D.E.M. (1991): Resolving Double Moral Hazard Problems with Buyout Agreements. Rand Journal of Economics, 22, pp. 232-240.

Eaton, Jonathan and Rosen, Harvey S. (1980): Taxation, Human Capital, and Uncertainty. American Economic Review, 70(4), pp. 705-715.

Financial Times (2010): Miliband hints at tax for graduates. September 27th, p. 2.

García-Peñalosa, Cecilia and Wälde, Klaus (2000): Efficiency and Equity Effects of Subsidies to Higher Education. Oxford Economic Papers, 52, pp. $702-722$.

Gary-Bobo, Robert J. and Trannoy, Alain (2005): Efficient Tuition Fees, Examinations and Subsidies. CEPR Discussion Paper DP5011.

\footnotetext{
${ }^{8}$ This is especially true in the USA. From a nationwide sample of 415 institutions of higher education, Cunningham and Cochi-Ficano (2002) calculate an average annual donation of US\$ 149 per alumnus.
} 
Romano, R. (1994): Double moral hazard and resale price maintenance. Rand Journal of Economics, 25, pp. 455-466.

Schmidt, F. L. and Hunter, J. E. (1998): The Validity and Utility of Selection Methods in Personnel Psychology - Practical and Theoretical Implications of 85 Years of Research Findings. Psychological Bulletin, 124, pp. 262-274.

The Economist (2005): Survey: Higher Education. September 8th.

Wolfstetter, E. (1999): Topics in Microeconomics. Cambridge University Press, Cambridge. 